\title{
Fusarium Wilt of Korean Blackberry Caused by Fusarium cugenangense
}

*Corresponding author

Tel: $+82-31-292-7848$

Fax: +82-31-292-7849

E-mail:wgkim5121@naver.com ORCID

https://orcid.org/0000-0003-1813-4480

\author{
Wan-Gyu Kim ${ }^{1 * \mathbb{D}}$, Hyo-Won Choi ${ }^{2}$, Gyun-Sung Park ${ }^{3}$, and Weon-Dae Cho ${ }^{1}$ \\ ${ }^{1}$ Global Agro-Consulting Corporation, Suwon 16614, Korea \\ ${ }^{2}$ Crop Protection Division, National Institute of Agricultural Sciences, Wanju 55365, Korea \\ ${ }^{3}$ Gochanggun Agricultural Technology Center, Gochang 56440, Korea
}

Received November 23, 2021

Accepted December 21, 2021

\begin{abstract}
Wilt symptoms were frequently observed in Korean blackberry (Rubus coreanus) plants grown in farmers' fields located in Gochang and Jeongeup, Jeonbuk Province, Korea during disease surveys in July 2020. The disease occurred in 10 of the 13 fields surveyed in the two locations. The incidence of diseased plants in the fields was $5-80 \%$. Seven isolates of Fusarium sp. were obtained from the diseased plants and examined for their morphological and molecular characteristics. All the isolates belonged to Fusarium oxysporum species complex based on the morphological characteristics but were identified as $F$. cugenangense based on the molecular characteristics. Two isolates of $F$. cugenangense were tested for pathogenicity on Korean blackberry plants by artificial inoculation. Pathogenicity of the two isolates on the plants was confirmed with the inoculation tests, which showed wilt symptoms similar to those observed in the diseased plants in the fields investigated. This is the first report of $F$. cugenangense causing Fusarium wilt in Korean blackberry.
\end{abstract}

Keywords: Fusarium cugenangense, Fusarium wilt, Korean blackberry, Pathogenicity, Rubus coreanus
Korean blackberry (Rubus coreanus) belonging to family Rosaceae is also called Bokbunja. The native range of the plant is China and Korea (Plants of the World Online, 2021). The plant is distributed not only in China and Korea, but also in Taiwan, Japan, and Austria (Bio Resource Information Service, 2021). The plant grows mainly in mountainous areas. Fruits of the plant are edible and also used for medicinal purposes, along with leaves and roots of the plant. In the central and southern regions of Korea, some farmers grow the plant in fields as a fruit tree.

Korean blackberry is a broadleaf shrub which blooms in May and bears fruits in June. Wilt symptoms were frequently observed in the plants grown in farmers' fields located in Gochang and Jeongeup, Jeonbuk Province, Korea during disease surveys in July 2020. In the early stages of the disease,

Research in Plant Disease

pISSN 1598-2262, elSSN 2233-9191

www.online-rpd.org the symptoms appeared as slight wilting of the plant leaves (Fig. 1A). The basal stems of the infected plants turned dark. In the late stages of the disease, the plants wholly wilted and blighted (Fig. 1B). Stems of the diseased plants turned black overall and rotted. Three sites were observed in a field, and twenty plants at each site were investigated for the disease incidence. The disease occurred in 10 of the 13 fields surveyed in the two locations (Table 1). The incidence of diseased plants in the fields was $5-80 \%$.

Fungal pathogen was isolated from diseased plants of Korean blackberry collected. The $3-5 \mathrm{~mm}$-long lesion pieces cut from stems of the diseased plants were plated on $2 \%$ water agar after surface-sterilizing with $1 \%$ sodium hypochlorite solution for one min. The fungal mycelia growing from the lesion pieces were transferred to potato dextrose agar slants after incubating the plates at $25^{\circ} \mathrm{C}$ for $2-3$ days. Seven isolates of Fusarium sp. were obtained from the lesion pieces of the diseased plants and examined for their morphological characteristics by a light microscope. Microconidia and 


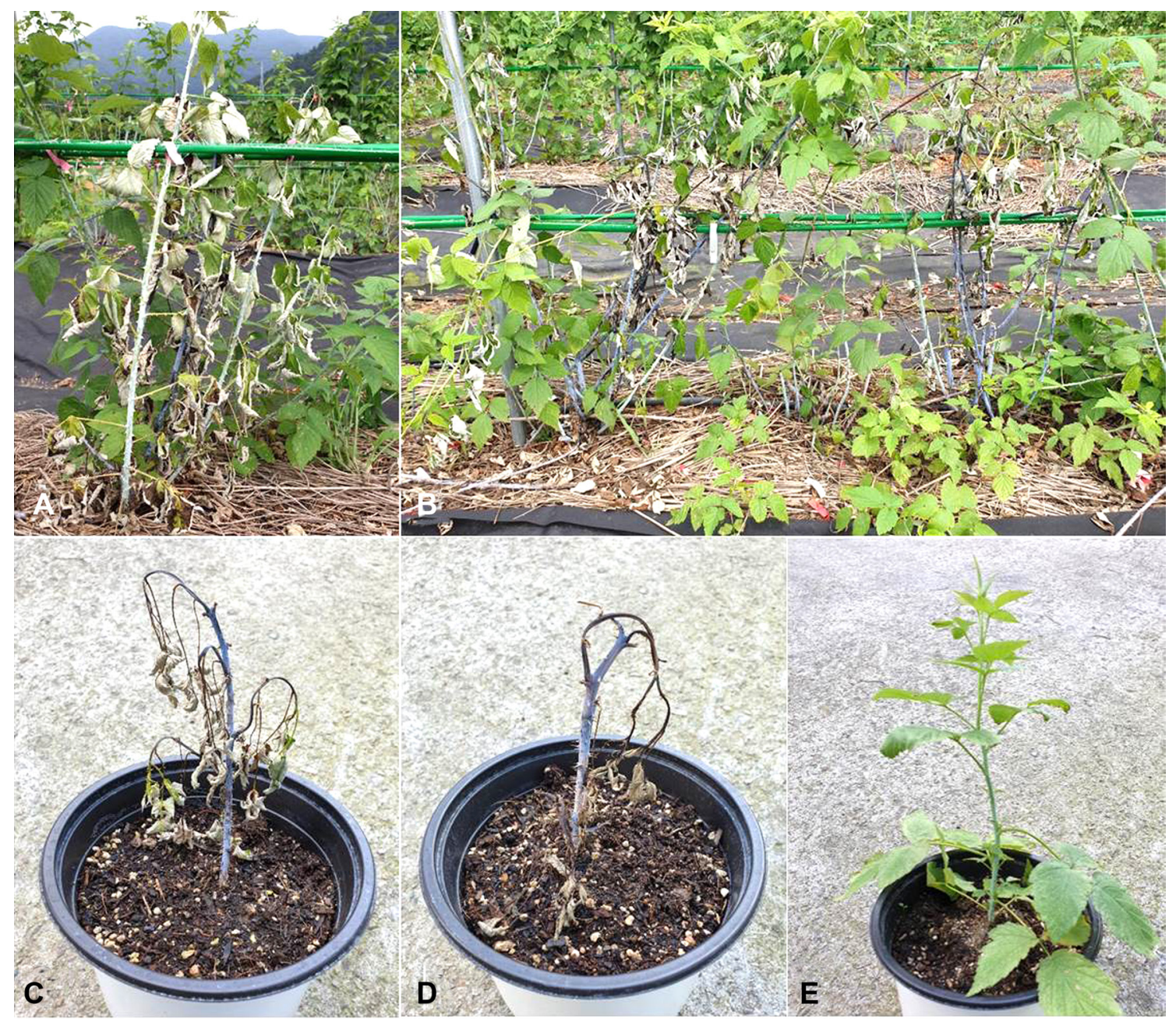

Fig. 1. Wilt symptoms of Korean blackberry plants. (A, B) Symptoms observed in the fields investigated. (C, D) Symptoms induced by artificial inoculation tests with Fusarium cugenangense isolates. (E) Non-inoculated plant (control).

Table 1. Occurrence of wilt disease on Korean blackberry plants grown in farmers' fields located in Gochang and Jeongeup, Jeonbuk Province, Korea in July 2020

\begin{tabular}{lccc}
\hline $\begin{array}{l}\text { Location } \\
\text { investigated }\end{array}$ & $\begin{array}{c}\text { No. of fields } \\
\text { investigated }\end{array}$ & $\begin{array}{c}\text { No. of fields } \\
\text { with wilt } \\
\text { disease }\end{array}$ & $\begin{array}{c}\text { \% diseased } \\
\text { plants }^{\text {a }}\end{array}$ \\
\hline Gochang & 7 & 4 & $5-80$ \\
Jeongeup & 6 & 6 & $5-30$ \\
\hline
\end{tabular}

${ }^{a}$ Three sites were observed in a field, and twenty plants at each site were investigated for the disease incidence.

macroconidia were produced on short monophialides (Fig. $2 \mathrm{~A}, \mathrm{~B})$. Microconidia were ellipsoidal to cylindrical, straight to curved, 0-1 septate, and measured 6.0-16.0×2.0-4.2 $\mu \mathrm{m}$ (av. $10.0 \times 3.0 \mu \mathrm{m}$ ). Macroconidia were falcate, foot-shaped at both ends, $2-5$ septate, and measured $18.7-42.1 \times 2.8-5.0 \mu \mathrm{m}$

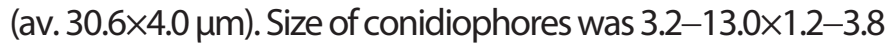
$\mu \mathrm{m}$ (av. $6.8 \times 2.4 \mu \mathrm{m})$. The morphological characteristics of the isolates were similar to those of Fusarium oxysporum described in previous studies (Booth, 1971; Domsch et al., 1993; Lombard et al., 2019).

To confirm the morphological identification of the seven isolates, DNA sequencing of the partial translation elongation factor 1-alpha (TEF) and RNA polymerase II largest subunit (RPB2) genes was analyzed. Genomic DNA was extracted from mycelium powder using the Maxwell RSC Cell DNA Purification kit (Promega, Madison, WI, USA). TEF and RPB2 genes were amplified from genomic DNA using primer sets of EF1/EF2 and 7cf/11ar, respectively (O'Donnell et al., 2010). Multiple sequence alignments of the two genes were carried out using Clustal W, and Neighbor-Joining tree for the combined dataset (total 1,486 bp) was generated us- 


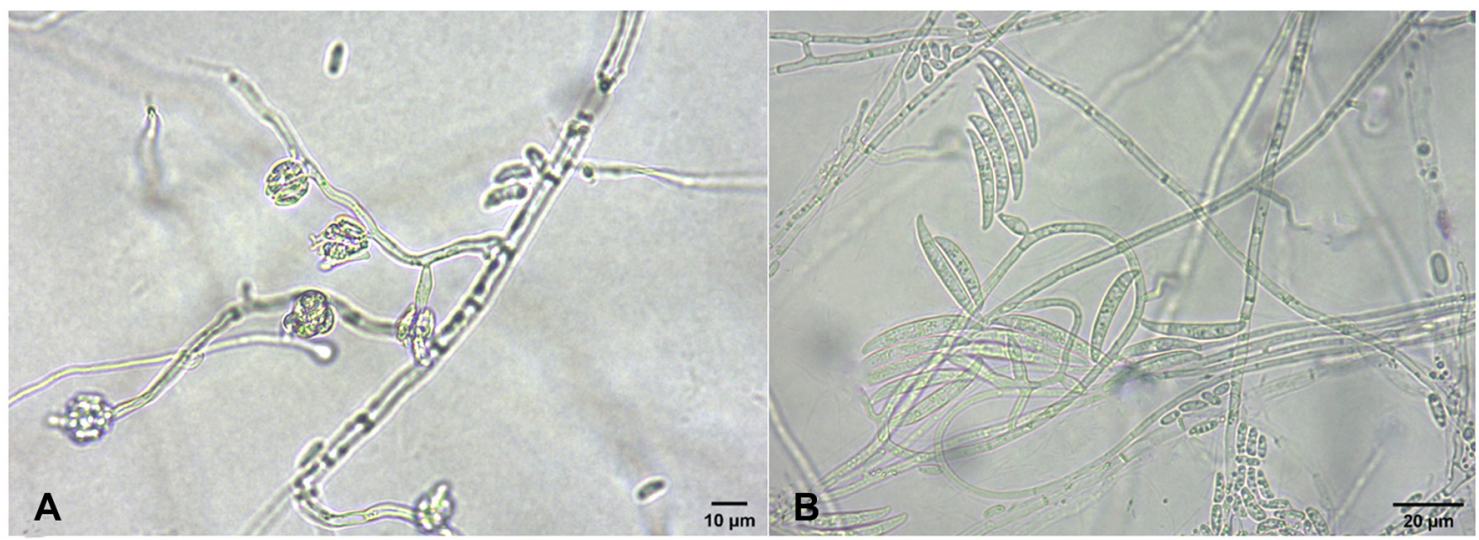

Fig. 2. Morphological features of Fusarium sp. isolates from diseased Korean blackberry plants. (A) Microconidia, monophialides, and hyphae of the isolate. (B) Microconidia, macroconidia, monophialides, and hyphae of the isolate.

ing MEGA X software (Kumar et al., 2018). The phylogenetic tree based on loci TEF and RPB2 combined sequence data showed that all the isolates were clustered in a group with Fusarium cugenangense strains (Fig. 3). The sequences of the two loci genes from the isolates were $99-100 \%$ identical to those of the reference strains of the GenBank database. The nucleotide sequences of TEF and RPB2 genes obtained from the seven isolates were deposited in NCBI GenBank with accession numbers of OK041485-OK041491 and OK041478OK041484, respectively.

The genus Fusarium contains many species complexes (O'Donnell et al., 2015). F. oxysporum is known to be a species complex, comprising of many species and clades (Achari et al., 2020; Baayen et al., 2000; O'Donnell et al., 1998). The

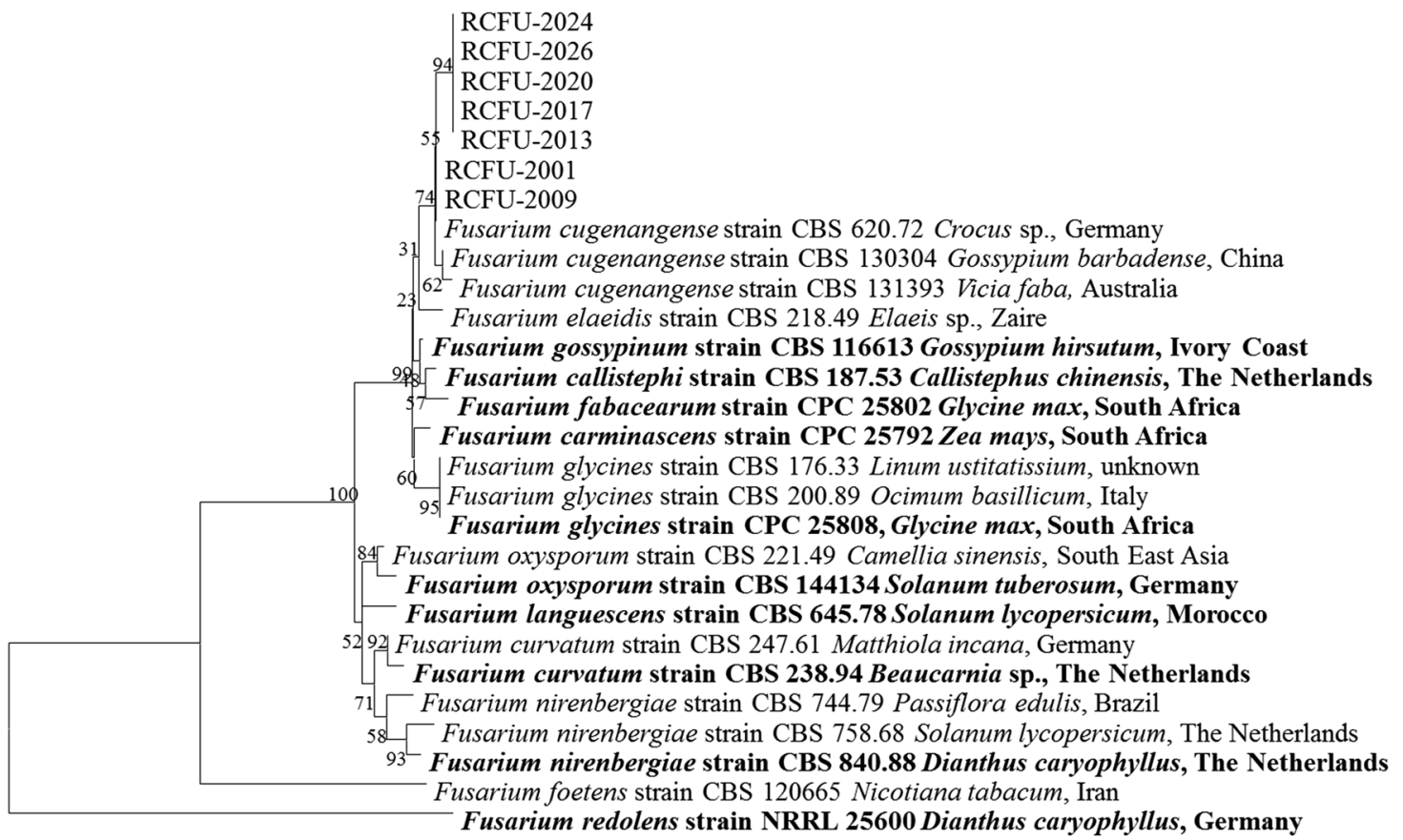

0.0050

Fig. 3. Phylogenetic tree based on the elongation factor 1 alpha (TEF) and RNA polymerase second largest subunit (rpb2) genes sequence dataset for Fusarium cugenangense isolates from diseased Korean blackberry and reference species. Sequence data were obtained from the NCBI GenBank database. The tree was generated using neighbor-joining analysis and Kimura 2-parameter model. The bar represents the number of nucleotide substitutions per site. Ex-type and Epitype cultures are indicated in bold. 
epitype of $F$. oxysporum was newly established using multilocus phylogenetic inference and subtle morphological differences (Lombard et al., 2019). In this study, Fusarium sp. isolates from diseased plants of Korean blackberry belonged to F. oxysporum species complex based on the morphological characteristics but were identified as F. cugenangense based on the molecular characteristics.

Among the seven isolates of $F$. cugenangense, two were tested for pathogenicity on Korean blackberry plants using artificial inoculation. Each isolate was cultured on cornmealsand medium ( $23 \mathrm{~g}$ cornmeal : $210 \mathrm{~g}$ sand : $60 \mathrm{ml}$ distilled water) in $500 \mathrm{ml}$-flasks for 50 days to prepare the inoculum. The inoculum was inoculated to two-month-old Korean blackberry plants that were grown in circular plastic pots (height, $15 \mathrm{~cm}$; upper diameter, $17 \mathrm{~cm}$; lower diameter, 10 $\mathrm{cm}$ ) in a vinyl greenhouse. For the inoculation test, surface soil around the plant was dug at a depth of $2-3 \mathrm{~cm}$, and 60 $\mathrm{g}$ of each inoculum was placed around the stem. The inoculated plant part was covered with the original soil. The same quantity of cornmeal-sand medium was used for the control plant. The inoculated plants were cultivated in a greenhouse at $24-30^{\circ} \mathrm{C}$. The inoculation test was performed in triplicate. Virulence of the isolates was rated based on the degree of wilt symptoms induced 15 days after inoculation.

The tested isolates of $F$. cugenangense induced wilt symptoms in the inoculated plants (Fig. 1C, D), whereas no symptoms were observed in the control plant (Fig. 1E). The symptoms induced by the artificial inoculation of plants were similar to those observed in the diseased plants in the fields investigated. The isolates that induced symptoms on the plants were re-isolated from the stem lesions.

It has been reported that $F$. oxysporum causes Fusarium wilt in blackberry (Rubus subgenus Rubus) (Gorden et al., 2016; Martin et al., 2017). In addition, the pathogen causing Fusarium wilt of blackberry was reported to have a forma specialis (Pastrana et al., 2017). F. cugenangense was first reported based on the phylogeny and genetic diversity of banana Fusarium wilt pathogen in Indonesia (Maryani et al., 2019). The pathogen has also been reported to cause diseases in Gossypium barbadense, Vicia faba, Crocus sp., and Musa sp. (Farr and Rossman, 2021). However, there has been no report on disease occurrence caused by the pathogen in Korean blackberry. This is the first report of $F$. cugenangense causing Fusarium wilt in Korean blackberry.

\section{Conflicts of Interest}

No potential conflict of interest relevant to this article was reported.

\section{Acknowledgments}

This study was supported by a research grant (PJ0145070 12020) from the Rural Development Administration, Korea.

\section{References}

Achari, S. R., Kaur, J., Dinh, Q., Mann, R., Sawbridge, T., Summerell, B. A. et al. 2020. Phylogenetic relationship between Australian Fusarium oxysporum isolates and resolving the species complex using the multispecies coalescent model. BMC Genomics 21: 248.

Baayen, R. P., O'Donnell, K., Bonants, P. J. M., Cigelnik, E., Kroon, L. P. N. M., Roebroeck, E. J. A. et al. 2000. Gene genealogies and AFLP analyses in the Fusarium oxysporum complex identify monophyletic and nonmonophyletic formae speciales causing wilt and rot disease. Phytopathology 90: 891-900.

Bio Resource Information Service. 2021. Resource information. URL https://www.bris.go.kr [20 November 2021].

Booth, C. 1971. The Genus Fusarium. Commonwealth Mycological Institute, Kew, Surrey, UK. 237 pp.

Domsch, K. H., Gams, W. and Anderson, T.-H. 1993. Compendium of Soil Fungi. Vol. I. IHW-Verlag, Eching, Germany. 859 pp.

Farr, D. F. and Rossman, A. Y. 2021. Fungal Databases, U.S. National Fungus Collections, ARS, USDA. URL https://nt.ars-grin.gov/fungaldatabases/ [20 November 2021].

Gorden, T. R., Kirkpatrick, S. C., Henry, P. M., Kong, M. and Broome, J. C. 2016. First report of a wilt disease of blackberry caused by Fusarium oxysporum in California. Plant Dis. 100: 1018.

Kumar, S., Stecher, G., Li, M., Knyaz, C. and Tamura, K. 2018. MEGA $\mathrm{X}$ : Molecular evolutionary genetics analysis across computing platforms. Mol. Biol. Evol. 35: 1547-1549.

Lombard, L., Sandoval-Denis, M., Lamprecht, S. C. and Crous, P. W. 2019. Epitypification of Fusarium oxysporum - clearing the taxonomic chaos. Persoonia 43: 1-47.

Martin, R. R., Ellis, M. A., Williamson, B. and Williams, R. N. 2017. Compendium of Raspberry and Blackberry Diseases and Pests. 2nd ed. The American Phytopathological Society, St. Paul, MN, USA. 175 pp.

Maryani, N., Lombard, L., Poerba, Y. S., Subandiyah, S., Crous, P. W. and Kema, G. H. J. 2019. Phylogeny and genetic diversity of the banana Fusarium wilt pathogen Fusarium oxysporum f. sp. cubense in the Indonesian centre of origin. Stud. Mycol. 92: 155194. 
O'Donnell, K., Kistler, H. C., Cigelnik, E. and Ploetz, R. C. 1998. Multiple evolutionary origins of the fungus causing Panama disease of banana: concordant evidence from nuclear and mitochondrial gene genealogies. Proc. Natl. Acad. Sci. USA 95: 2044-2049.

O'Donnell, K., Sutton, D. A., Rinaldi, M. G., Sarver, B. A., Balajee, S. A., Schroers, H.-J. et al. 2010. Internet-accessible DNA sequence database for identifying fusaria from human and animal infections. J. Clin. Microbiol. 48: 3708-3718.

O'Donnell, K., Ward, T. J., Robert, V. A. R. G., Crous, P. W., Geiser, D. M. and Kang, S. 2015. DNA sequence-based identification of Fu- sarium: Current status and future directions. Phytoparasitica 43: 583-595.

Pastrana, A. M., Kirkpatrick, S. C., Kong, M., Broome, J. C. and Gorden, T. R. 2017. Fusarium oxysporum f. sp. mori, a new forma specialis causing Fusarium wilt of blackberry. Plant Dis. 101: 20662072.

Plants of the World Online. 2021. Rubus coreanus Miq. Royal Botanic Garden, Kew. URL https://powo.science.kew.org/ [20 November 2021]. 